\title{
Therapeutic Mild Hypothermia and the Pharmacokinetics of Drugs in Trauma Brain Injury (TBI) Patients with a Focus on Sedation, Anticonvulsant and Antibiotic Therapy
}

\author{
F. Carlotta Bagna ${ }^{1}$, Sara Pitoni ${ }^{2}$ and Peter J.D. Andrews ${ }^{*}, 3$ \\ ${ }^{I}$ Anesthesiology and Intensive Care Resident- Department of Anestesiology and Intensive Care Medicine, University of \\ Turin, Ospedale S. Giovanni Battista, Torino, Italy \\ ${ }^{2}$ Anesthesiology and Intensive Care Resident - Department of Anesthesiology and Intensive Care Unit, Policlinico \\ Universitario "Agostino Gemelli" - Università Cattolica del Sacro Cuore of Rome, Italy \\ ${ }^{3}$ Department of Anaesthesia and Pain Management, University of Edinburgh, Scotland, UK
}

\begin{abstract}
Background: Therapeutic hypothermia may alter both the pharmacokinetic (PK) and dynamics (PD) of the commonly used drugs in critical care. To achieve maximum benefit, medication dosage and schedules should be optimized.

Objective: To review the existing scientific evidence showing the effect of therapeutic hypothermia on the pharmacokinetics of drugs commonly used in the care of patients after Trauma Brain Injury (TBI); particularly including sedatives, anticonvulsants and antibiotics.

Data Sources: Computerized searches of OVID MEDLINE, OVID EMBASE, Cochrane Clinical Trials Register to August 2013 and hand searching of references of retrieved articles and proceedings of meetings; associated reference lists; and articles identified by experts in the field.

Study Selection: Inclusion criteria were as follows: a) population- humans or animals undergoing therapeutic hypothermia b) design-prospective, randomized controlled trial, c) intervention-hypothermia; measurement of PD and PK of different drugs.

Data Extraction: A data extraction form was used and authors (CB \& SP) reviewed all trials.

Data Synthesis: We reviewed 30 trials that documented changes in PD and PK of sedatives (propofol and midazolam), opioids (fentanyl, remifentanil, alfentil and morphine), anticonvulsants (phenytoin) and antibiotics (aminoglycosides) conducted in human or animal models undergoing therapeutic hypothermia.

Conclusion: Data show that therapeutic hypothermia significantly alters the pharmacokinetics of commonly used agents. Particular care should be taken to reduce sedatives once target temperature is reached. Further clinical studies are required to clarify the effect of hypothermia on the PD and PK of therapeutic agents to optimize the benefits of therapeutic hypothermia in the treatment of TBI patients.
\end{abstract}

Keywords: Trauma brain injury (TBI), therapeutic hypothermia (TH), pharmacokinetics (PK), pharmacodynamics (PD).

\section{INTRODUCTION}

Understanding the effects of hypothermia on drug metabolism is crucial when optimizing its application and will increase the quality of patient care. Particularly as critical care patients receive, on average, twice the number of medications compared with patients on general medical wards [1] and this increases the possibility of drug interactions and toxicity. Most of the drugs used in critical care are metabolized by the liver and the Cytochrome P450 system (CYP450). The CYP450 is a large and diverse group

*Address correspondence to this author at the Western General Hospital, Crewe Road South, Edinburgh, EH4 2XU, UK;

Tel: +44 (0)131-5371666; Fax: +44 (0)131-5371021;

E-mails: p.andrews@ed.ac.uk,eurotherm.3235@ed.ac.uk of enzymes belonging to the superfamily of proteins containing a heme cofactor. They form part of multicomponent ubiquitous transfer chains and in the liver are critical to metabolizing a wide variety of drugs and toxic compounds [2].

Therapeutic hypothermia (TH) is a promising intervention in the management of a number of acute brain injury syndromes including; traumatic brain injury [3-5], following cardiac arrest [6-8], ischemic stroke [9], neonatal asphyxia [10], subarachnoid haemorrhage and during some neurosurgical procedures. After cardiac arrest, with an initial rhythm of ventricular fibrillation, the treatment is now recommended by NICE, the European Resuscitation Council and the American Heart Association [8]. The data on effectiveness of TH following traumatic brain injury (TBI) is 
less robust, due largely to small, poor quality trials $[3,11$ 15].

Key elements for the successful use of TH are awareness and proper management of the physiological consequences and side-effects of treatment. Untreated or poorly managed complications may negate any potential benefits of treatment $[2,11,12,16]$.

Since most enzymatic processes exhibit temperature dependency, it is reasonable to expect therapeutic hypothermia will cause alterations in pharmacokinetic and dynamic (PK and PD) parameters, leading to an increased risk of drug toxicity or therapy failure [17]. Generalisable knowledge about the effect of therapeutic hypothermia on pharmacokinetics and pharmacodynamics will lead to more appropriate dosing and effective therapy $[2,18]$.

\section{SUMMARY OF POTENTIAL EFFECTS OF HYPOTHERMIA}

Hypothermia modulates many different post acute brain injury processes, some of which may be responsible for secondary brain damage. For example, hypothermia reduces the pro-inflammatory response and can lead to an improvement in brain tolerance of ischemia, hypoperfusion and reperfusion damage. It is also associated with a decrease in free radicals release and a reduced activation of the apoptotic pathway. Historically, reduction of the systemic and cerebral metabolic rate through therapeutic hypothermia, even when coupled with mild metabolic acidosis, is considered one of the most important mechanisms to reduce damage and is still regarded as such today $[18,19]$. TH also causes a reduction in blood-brain barrier disruption and a decrease in vascular permeability which reduces the formation of edema [2].

Hypothermia is however, characterized by several important side-effects, and failure to adequately manage them is believed to be responsible for the failure to replicate the effectiveness of $\mathrm{TH}$ in experimental studies in clinical trials in TBI. The relevant side effects of therapeutic hypothermia are summarized in Table $\mathbf{1}$.

Table 1. Common Side Effects of Therapeutic Therapeutic Hypothermia

- $\quad$ Shivering

- Hyperglycemia and decreased insulin sensitivity

- Depletion of electrolyte levels: hypoK ${ }^{+}$, hypo $\mathrm{Mg}^{++}$, hypoPhosphatemia

- Decreased metabolic rate, $\mathrm{pO}_{2}$ and $\mathrm{pCO}_{2}$ level and increase in $\mathrm{pH}$

- Hemodynamic instability

- Mild coagulopathy

- Rising infection risk : VAP, surgical wound infection, catheterrelated infections.

- Altered drug pharmacokinetics (PK) and pharmacodynamics (PD)

- Mild rise in free fatty acids, ketones, lactate, glycerol, amylase and liver enzymes

\section{OBJECTIVES OF THIS PAPER}

The objective of this paper is to review the existing scientific evidence showing the effect of therapeutic hypothermia on the pharmacokinetics of drugs commonly used in the care of patients after Trauma Brain Injury (TBI); particularly including sedatives, anticonvulsants and antibiotics.

\section{METHODS}

\section{Data Sources}

Computerized searches of OVID MEDLINE, OVID EMBASE, Cochrane Clinical Trials Register to August 2013 and hand searching of references of retrieved articles and proceedings of meetings; associated reference lists; and articles identified by experts in the field.

\section{Study Selection}

Inclusion criteria were as follows: a) population- humans or animals undergoing therapeutic hypothermia b) designprospective, randomized controlled trial, c) interventionhypothermia; measurement of PD and PK of different drugs. Search terms included: Traumatic Brain Injury; Head Injury; Therapeutic hypothermia; Pharmacokinetic(s), clinical and population; Pharmacodynamic(s), clinical and population; half life; drug clearance.

\section{Data Extraction}

A data extraction form was used and authors (CB \& SP) reviewed all trials.

\section{Data Synthesis}

We reviewed 30 trials that documented changes in PD and PK of sedatives (propofol and midazolam), opioids (fentanyl, remifentanil, alfentil and morphine), anticonvulsants (phenytoin) and antibiotics (aminoglycosides) conducted in human or animal models undergoing therapeutic hypothermia.

\section{RESULTS}

\section{Cytochrome P450 Enzyme System}

There are few studies conducted to specifically clarify the effect of hypothermia on the disposition and response of medications. Tables $\mathbf{2}$ and $\mathbf{3}$. Nevertheless, some small studies, on animals and humans, have highlighted the key role of CYP450 activity variation in metabolising drugs in mild-to-moderate hypothermia [2, 20, 21]. Collectively, these studies have shown that hypothermia decreases the clearance of drugs through a reduction in hepatic elimination.

Studies conducted on humans during anaesthesia have previously reported an increased duration of action of vecuronium during mild hypothermia and a decreased rate of recovery $[22,23]$. The increased duration of action cannot be explained by PD factors, as TH has been reported to not alter the plasma concentration-effect mechanism, and it is therefore likely due to altered distribution and elimination (PK variables). Fukuoka et al. have shown a five-fold increase in plasma concentrations of midazolam when the core temperature of brain-injured patients was maintained $<35^{\circ} \mathrm{C}$ confirming that hypothermia decreases the clearance (CL) of certain hepatically eliminated drugs [20].

Tortorici et al. found that mild to moderate hypothermia decreases the systemic clearance of CYP450-metabolized drugs between 7 and $22 \%$ per degree Celsius below $37^{\circ} \mathrm{C}$. 
Table 2. Effect of Therapeutic Hypothermia on Drugs PK

\begin{tabular}{|c|c|c|c|c|c|}
\hline \multirow{2}{*}{ Study } & \multirow{2}{*}{ Species and Model } & \multirow{2}{*}{ Drug } & \multirow{2}{*}{ Thermic Regimen } & \multicolumn{2}{|l|}{ PK Parameter } \\
\hline & & & & CL & Vd \\
\hline Tortorici et al. & $\begin{array}{l}\text { Rat; in vitro }(\mathrm{n}=8) \\
\text { Rat; in vivo }(\mathrm{n}=6)\end{array}$ & $\begin{array}{l}\text { Chlorzoxazone } \\
\text { Chlorzoxazone }\end{array}$ & $\begin{array}{l}\text { Severe HT } \\
\left(37^{\circ} \mathrm{C} \text { vs } 30^{\circ} \mathrm{C}\right) \\
\text { Severe HT } \\
\left(37^{\circ} \mathrm{C} \text { vs } 30^{\circ} \mathrm{C}\right)\end{array}$ & $\begin{array}{l}\text { Km increased } 116 \% \\
\text { Vmax unaltered } \\
\text { CLint, of CYP2E1 decreased } 44 \% \\
\text { CL decreased } 54 \% \\
\text { ke decreased } 66 \% \\
\text { Urinary metabolite excretion decreased } 76 \%\end{array}$ & Increased $27 \%$ \\
\hline Leslie et al. & Human; in vivo $(\mathrm{n}=6)$ & Propofol & $\begin{array}{l}\text { Moderate HT } \\
\left(37^{\circ} \mathrm{C} \text { vs } 34^{\circ} \mathrm{C}\right)\end{array}$ & CL decreased $25 \%(\mathrm{NS})$ & - \\
\hline Fukoka et al. & Human; in vivo $(\mathrm{n}=15)$ & Midazolam & $\begin{array}{l}\text { Moderate HT } \\
\left(37^{\circ} \mathrm{C} \text { vs } 32^{\circ}-34^{\circ} \mathrm{C}\right)\end{array}$ & CL decreased $99.4 \%$ & Increased $83 \%$ \\
\hline Bansinath et al. & $\mathrm{Dog}$; in vivo $(\mathrm{n}=18)$ & Morphine & $\begin{array}{l}\text { Severe } \mathrm{HT} \\
\left(37^{\circ} \mathrm{C} \text { is } 30^{\circ} \mathrm{C}\right)\end{array}$ & CL decreased $70 \%$ & Decreased $33 \%$ \\
\hline Roka et al. & Human; in vivo $(\mathrm{n}=16)$ & Morphine & $\begin{array}{l}\text { Moderate HT } \\
\left(37^{\circ} \mathrm{C} v s 32^{\circ}-34^{\circ} \mathrm{C}\right)\end{array}$ & CL decreased $22 \%$ & - \\
\hline Fritz et al. & Pig; in vitro $(\mathrm{n}=6)$ & Fentanyl & $\begin{array}{l}\text { Severe HT } \\
\left(37.7^{\circ} \mathrm{C} \text { vs } 31.6^{\circ} \mathrm{C}\right)\end{array}$ & $\begin{array}{l}\text { Conversion rate of CYP } 3 \mathrm{~A} 4 \text { decreased } \\
31 \% \text { at } 32^{\circ} \mathrm{C} \text { and } 56 \% \text { at } 26^{\circ} \mathrm{C} \text { ) }\end{array}$ & - \\
\hline Iida et al. & Human; in vivo $(\mathrm{n}=14)$ & Phenytoin & $\begin{array}{l}\text { Moderate HT } \\
\left(37^{\circ} \mathrm{C} \text { vs } 34^{\circ} \mathrm{C}\right)\end{array}$ & $\begin{array}{l}\text { CL decreased } 67 \% \\
\text { ke decreased 50\% } \\
\text { Metabolite plasma concentration decreased (NP) }\end{array}$ & Unaltered \\
\hline Koren et al. & Pig; in vivo $(\mathrm{n}=7)$ & Gentamicin & $\begin{array}{l}\text { Severe HT } \\
\left(37^{\circ} \mathrm{C} \text { vs } 29^{\circ} \mathrm{C}\right)\end{array}$ & $\begin{array}{l}\text { CL decreased } 51 \% \\
\text { ke decreased } 27 \%\end{array}$ & Decreased $32 \%$ \\
\hline Satas et al. & Pig; in vivo $(\mathrm{n}=16)$ & Gentamicin & $\begin{array}{l}\text { Moderate } \mathrm{HT} \\
\left(39^{\circ} \mathrm{C} \text { vs } 35^{\circ} \mathrm{C}\right)\end{array}$ & CLr unaltered & - \\
\hline
\end{tabular}

Impaired clearance is the most striking effect of $\mathrm{TH}$, resulting in drug and metabolite accumulation with a subsequent reduction in TD50 (median toxic dose) and therapeutic index of most commonly used drugs following TBI. This can lead to increased side effects of therapeutic hypothermia and reducing its potential benefits [18].

Hepatic microsomal cytochrome P450 3A4 (CYP3A) activity tested in vitro by ethylmorphine $\mathrm{N}$-demethylation was shown to be temperature dependent. Hypothermia induced a strong temperature-dependent reduction in hepatic CYP3A activity (48\% vs 32\%) [17].

The most commonly used drugs in patients after TBI are sedatives, hypnotics, analgesics, anti-convulsants and antibiotics.

\section{Sedatives: Propofol and Midazolam}

Propofol is commonly used in intensive care medicine and has a high hepatic extraction ratio. Its PK during mild hypothermia was studied by Leslie et al. in two different studies on healthy volunteers and on neurosurgical patients [24, 25]. Propofol blood concentration increased by approximately $28 \%$ and the inter-compartmental clearances decreased at $34^{\circ} \mathrm{C}$ compared with $37^{\circ} \mathrm{C}$. Total Body Clearance (TBC), central and compartmental distribution volumes $(\mathrm{Vd})$ are not significantly modified by temperature. Hepatic blood flow decreased during propofol administration but no significant change in hepatic blood flow was caused by hypothermia. Hypothermia significantly alters the concentration present at the drug effect site, decreasing propofol partitioning between the central and peripheral compartments, and intercompartmental clearances are decreased in the presence of hypothermia [2, 24, 26]. In an RCT conducted in 40 neurosurgical patients, Leslie et al. compared Propofol blood levels and bispectral index (BIS) value at the $\mathrm{CP50}$-awake of propofol at $34^{\circ} \mathrm{C}$. Propofol concentration, but not the core temperature, predicted the responsiveness to command and noted that core temperature did not alter the relationship between BIS and response to command [25]. Thus BIS monitoring during Propofol anaesthesia and or sedation remains reliable during $\mathrm{TH}$.

Midazolam is a frequently used benzodiazepine in ICU with sedative and anticonvulsant properties. A 5-fold increase in blood concentration due to a nearly $100 \%$ decrease in systemic clearance (CL) during hypothermia was reported in patients following TBI, when administered by a continuous infusion [20]. These data are however, challenged by two recent, small observational studies [26, 27].

\section{Opioid Analgesics: Fentanyl, Remifentanil, Alfentanil and Morphine}

Fentanyl is a commonly used opioid analgesic in ICU. It is characterized by a high hepatic extraction ratio and a large volume of distribution. Its $\mathrm{PK}$ during $\mathrm{TH}$ has been extensively studied in experimental animal models. Two of these studies showed a consistent increase in Fentanyl blood concentration during hypothermia, persisting for more than 6 hours after rewarming. Increased blood concentration can be explained by two mechanisms: reduced bio-transformation rates and CL coupled with a reduced volume of distribution of Fentanyl. The reduced bio-transformation can be partly attributed to a reduction in organ perfusion/ blood flow and 
Table 3. Hypothermia Specific Effects on Various Commonly Used Drugs

\begin{tabular}{|c|c|c|c|}
\hline Medication & Hypothermia Effect & Impact & Reference \\
\hline \multicolumn{4}{|l|}{ Opioid } \\
\hline $\begin{array}{l}\text { Remifentanil } \\
\text { Fentanyl }^{3}\end{array}$ & $\begin{array}{c}\downarrow \text { Clearance } \\
\downarrow \text { Volume of distribution }\end{array}$ & $\downarrow$ Dosage $(30 \%)^{2}$ & {$[17,30,44]$} \\
\hline Morphine $^{3}$ & $\begin{array}{l}\uparrow \text { Plasma concentration } \\
\uparrow \text { Half-life of elimination }\end{array}$ & $\begin{array}{l}\downarrow \text { Dosage }(30 \%) \\
\text { Slower titration }\end{array}$ & {$[36]$} \\
\hline \multicolumn{4}{|l|}{ Sedation } \\
\hline Propofol $^{1}$ & $\uparrow$ Plasma concentration & $\downarrow$ Dosage $(30 \%)$ & {$[24,44]$} \\
\hline Midazolam $^{1}$ & $\begin{array}{c}\uparrow \text { Plasma concentration } \\
\uparrow \text { Volume of distribution } \\
\downarrow \text { Clearance }\end{array}$ & $\downarrow$ Dosage & {$[20]$} \\
\hline \multicolumn{4}{|c|}{ Neuromuscular Blocker } \\
\hline $\begin{array}{l}\text { Vecuronium }^{1} \\
\text { Rocuronium }^{1}\end{array}$ & $\begin{array}{c}\downarrow \text { Clearance } \\
\uparrow \text { Time before effect }\end{array}$ & $\begin{array}{l}\downarrow \text { Dosage }(30 \%) \\
\text { Monitor }\end{array}$ & {$[45,46]$} \\
\hline Atracurium $^{1}$ & $\downarrow$ Clearance & Delayed intubation & {$[47,48]$} \\
\hline \multicolumn{4}{|c|}{ Vasoactive Medication } \\
\hline Glyceryl trinitrate $^{1}$ & $\downarrow$ Clearance & $\downarrow$ Dosing after effect & {$[49]$} \\
\hline \multicolumn{4}{|l|}{ Anticonvulsants } \\
\hline phenytoin ${ }^{1}$ & $\begin{array}{c}\downarrow \text { Clearance } \\
\downarrow \text { Plasma concentrations of total and unbound drug }\end{array}$ & $\begin{array}{c}\qquad \downarrow \text { Dosage } \\
\text { Adjust according to serum concentration measurements }\end{array}$ & [39] \\
\hline
\end{tabular}

${ }^{1}$ Experiments on humans.

${ }^{2}$ Recommendation concerning maintenance therapy.

${ }^{3}$ Experiments on animals.

partly to a decreased cytochrome activity. End organ arterial blood flows, such as total hepatic blood flow, are markedly decreased by hypothermia. However, hepatic arterial blood flow is the only organ perfusion to remain unaltered.

The blood concentration of fentanyl increases during therapeutic hypothermia and may contribute to secondary brain damage due to three mechanisms; fentanyl is not particularly effective at reducing the stress response due to $\mathrm{TH}$, furthermore it fails to blunt post-traumatic excitotoxicity and it may also reduce CBF. In patients with partial complex epilepsy fentanyl can induce seizures even in the "healthy temporal lobe" [29]. Additionally, two different studies have demonstrated that hypothermia in fentanyl-anesthetized rats was detrimental in traumatic brain injury and cerebral ischemia [29].

PK studies have been conducted in humans during mild to moderate hypothermia during cardiopulmonary bypass (CPB) surgery, in both adult and pediatric patients. They confirmed that Fentanyl metabolism, by the cytochrome system, is severely impaired [17, 28] (Fig. 1). Most of these studies were performed during CBP, making it difficult to determine whether changes in PK were the result of hypothermia itself or due to extracorporeal circulation.

New studies are required to clarify the role of fentanyl administration in influencing neurological outcome during therapeutic hypothermia therapy.
Remifentanil is a potent $\mu$-agonist at the opioid receptor. Its $\mathrm{PK}$ is different from other opiates because it has a very short half-time and its elimination is due to nonspecific blood and tissue esterases. All the recent studies on remifentanil in hypothermia have been conducted on patients undergoing $\mathrm{CPB}[30,31]$. Remifentanil $\mathrm{PK}$ is modified during hypothermic $\mathrm{CPB}$ by hemodilution, altered protein binding, uptake (adsorption) of drugs by the circuit and isolation of lungs from the circulation. Michelsen et al. [30] showed a decrease in the elimination/ clearance (CLe) during hypothermia: there is a proportional decrease of $6.37 \%$ in CLe with each degree Celsius decrease in temperature below $37^{\circ} \mathrm{C}$, likely due to decreased enzyme activity in blood and tissue with decreasing temperature.

Alfentanil is a $\mu$ opioid receptor agonist frequently used in anesthetic practice and in ICU. Some pharmacokinetics parameters, including the steady-state volume of distribution, are similar to remifentanil with the substantial difference that alfentanil has a significantly reduced central clearance. Pharmacodynamically both require a similar time for equilibrium to be reached between blood and effect-site concentration, but Alfentanil is 19 times less potent than remifentanil [32]. Alfentanil administration during hypothermia has been demonstrated useful in reducing vasoconstriction and shivering thresholds linearly as a function of dose [33]. No critical care pharmacokinetic studies on alfentanil administration during hypothermia treatment in animals or humans have been conducted. Petros 
et al. have studied Alfentanil PK after therapeutic hypothermia in three groups of patients, all undergoing thoracic surgery: two groups of patients underwent cardiac surgery with hypothermia $\left(26.3^{\circ} \mathrm{C}\right.$ and $\left.33.9^{\circ} \mathrm{C}\right) \mathrm{CPB}$ technique and a group of control patients underwent lateral thoracotomy for pulmonary diseases. The mean temperature of each group at the end of CPB did not differ significantly when alfentanil was administered. There were no significant differences in terms of Clearance and in distribution volumes [34].

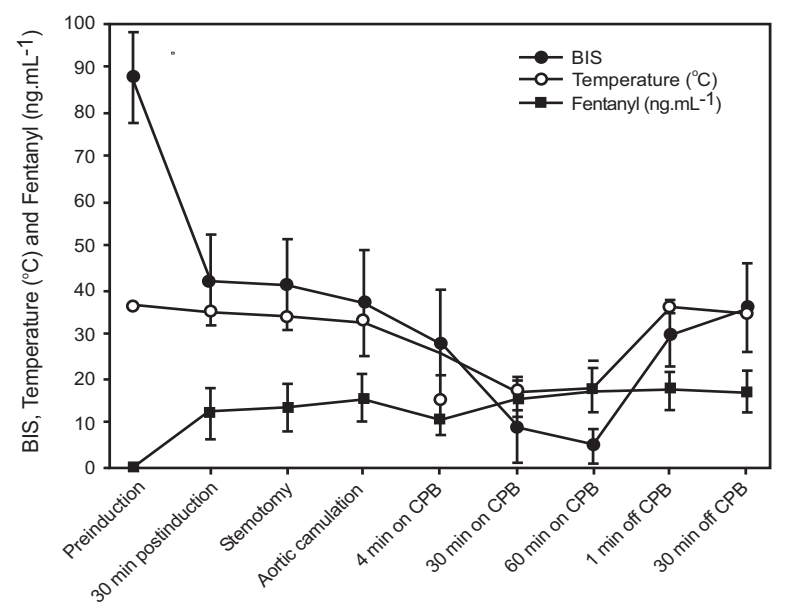

Fig. (1). Changes in BIS, plasma fentanyl, and nasopharyngeal temperature. Data are mean \pm SD. Data are based on $n=15$ except preinduction $(\mathrm{n}=5)$. BIS, bispectral index. $\mathrm{CPB}$, cardiopulmonary bypass. For BIS preinduction to 30 minutes postinduction $(\mathrm{p}=$ 0.02 ), aortic cannulation to 30 minutes on $\mathrm{CPB}$ ( $\mathrm{p}<0.001$ ), and 60 minutes on $\mathrm{CPB}$ to 1 minute off $\mathrm{CPB}(\mathrm{p}<0.001)$. Kussman $\mathrm{BD}$, Zurakowski D, Sullivan L, et al: Evaluation of plasma fentanyl concentrations in infants during cardiopulmonary bypass with lowvolume circuits. J Cardiothorac Vasc Anesth 2005; 19: 316-321.

Morphine PK and cardiovascular effects have been studied in animals and humans in hypothermic conditions. Two studies performed on isoflurane anaesthetised dogs highlighted the key morphine $\mathrm{PK}$ variation during hypothermia when $1 \mathrm{mg} / \mathrm{kg}$, was administered intravenously. At $30^{\circ} \mathrm{C}$ dogs showed significantly higher levels of morphine both in plasma and cerebrospinal fluid coupled with a reduction in total body Clearance and increased main residence time (MRT). Body temperature did not affect the $t_{1 / 2}$ alpha, while $t_{1 / 2}$ beta was increased. The distribution volume at steady state was decreased $[35,36]$.

Hypothermia also influences Morphine PD; a study on a pig ileum preparation has demonstrated that decreasing body temperature to $30{ }^{\circ} \mathrm{C}$ can reduce Morphine potency when compared to $37^{\circ} \mathrm{C}$. This reduction in potency may be related to a reduction in receptor affinity, demonstrated by a six-fold increase in the dissociation constant of Morphine for the $\mu$ receptor [37]. Hypothermia increases Morphine plasma level and globally reduces its potency [2]. A randomized controlled study in neonates of moderate whole-body mild hypothermia after perinatal asphyxia has confirmed that serum Morphine concentrations after continuous infusion are higher in hypothermia-treated infants than in the control group despite a similar rate of infusion and cumulative doses in both groups. Morphine clearance was reduced in both groups. Contingent toxic effects related to elevated serum drug levels remain to be clarified [38].

Caution should be exercised when translating cardiopulmonary bypass data to adult critical care because the steady-state volume of distribution (Vss) increases with the institution of CPB because of hemodilution(30), substantially altering PK.

\section{Anticonvulsant: Phenytoin}

Phenytoin is one of the most commonly used anticonvulsant drugs in ICU. It's hepatic clearance depends on both the unbound drug fraction concentration and on the activity rate of hepatic enzymes. Hepatic blood flow variation has little influence on phenytoin elimination clearance. The fraction bound to albumin is $90 \%$ and Phenytoin activity is dependant on its unbound drug fraction. The unbound fraction has been shown to be increased in critically ill patients and is inversely related to serum albumin concentration. Phenytoin hepatic elimination is principally due to the hydroxylation to 5-p-HPPH through a reaction catalized by CYP2C9 and CYP2C19. The elimination kinetics of this reaction can saturate at the therapeutic blood concentration of phenytoin and is governed by the Michaelis-Menten formula. It is therefore mandatory to use strict blood level monitoring to guided therapy.

Phenytoin metabolism is influenced by several drugs, such as amiodarone, midazolam, antibiotics, vecuronium and barbiturates. The effect of mild hypothermia on phenytoin in patients following TBI has been examined by Iida et al. [39] who found that hypothermia significantly increased the plasma concentrations of total and unbound phenytoin. Moreover TH was able to reduce the elimination constant (ke) and elimination clearance by $50 \%$ and $67 \%$ respectively; additionally the concentration of it's major metabolite 5-p-HPPT was reduced, suggesting an inhibition in phenytoin's metabolism.

Our own data (Edinburgh, unpublished data) show hypothermia is associated with a significant effect on the corrected plasma phenytoin concentration with time. Corrected phenytoin levels were available on 15 patients, 8 hypothermia and 7 controls (enrolled in the Eurotherm3235Trial). Median sampling time was 4 days (range 3 to 10 days) and 5 days (range 4 to 10 days) for hypothermia $v s$ control respectively, $\mathrm{p}=0.336$. In the hypothermia group corrected phenytoin concentration increased with time from $13.0 \pm 1.4 \mathrm{mg} / 1$ on day 1 to $15.5 \pm$ $2.2 \mathrm{mg} / \mathrm{l}$ on day 8 . Conversely in the control group corrected phenytoin concentration fell from $18.4 \pm 2.4 \mathrm{mg} / 1$ to $10.2 \pm$ $1.8 \mathrm{mg} / \mathrm{l}$ over the same interval. Two way ANOVA revelled a significant effect of treatment allocation on phenytoin levels, $\mathrm{p}<0.001$. Pair wise multiple comparison indicated a significant interaction between time and treatment on days 1 , 5,7 and 10 of admission, $\mathrm{p}<0.05$ (Fig. 2).

\section{Antibiotics}

Hypothermia has been demonstrated to inhibit leukocyte migration and phagocytosis and decreases the synthesis of proinflammatory cytokines. The suppression of inflammation is considered one of the most important 
protective mechanisms of hypothermia on injured brain, but may also lead to an increased risk of infection [2].

Mean +/- SEM Phenytoin Concentration

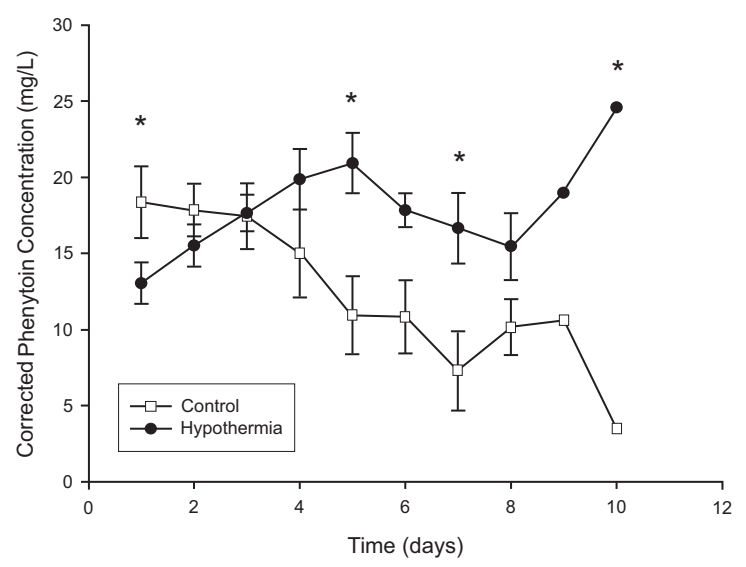

Fig. (2). Phenytoin pharmacokinetics in properly and prospectively randomized patients to hypothermia or normothermia [50].

Few PK studies have been conducted on antibiotics during therapeutic hypothermia. However, some studies have assessed the PK of aminoglycosides, such as gentamicin and netilmicin, in animals and humans [17, 40, 41]. Gentamicin is almost completely excreted renally and is unchanged. It has a nephrotoxic and ototoxic effect and because of this, needs strict monitoring of blood levels. Two studies in piglet models evaluated the PK of gentamicin during mild hypothemia. Koren et al. [17] found that this antibiotic, administrated by bolus at $29^{\circ} \mathrm{C}$, results in an increase in serum concentration, prolonged elimination half-time and reduced total body clearance. The volume of distribution and the volume of the central compartment seem to be significantly decreased by TH (Fig. 3). The authors reported

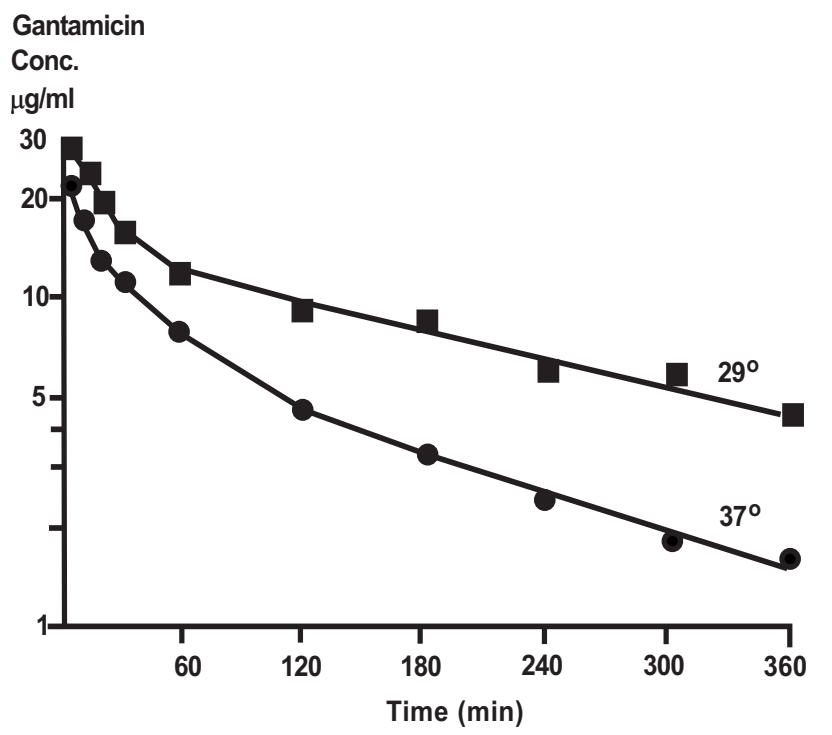

Fig. (3). Concentration-time curve of gentamicin given intravenously as a bolus of $5 \mathrm{mg} / \mathrm{kg}$ during normothermia and hypothermia $\left(29^{\circ} \mathrm{C}\right)$. Koren G, Barker C, Bohn D et al. Influence of hypothermia on the pharmacokinetics of gentamycin and the theophylline in piglets. Crit Care Med1985; 13(10): 844-7. a reduction in cardiac output during the induction of hypothermia in a temperature-dependent fashion, which may be responsible for a decrease in glomerular filtration rate [17]. A recent retrospective study examining 55 infants with hypoxic-ischemic encephalopathy treated with $72 \mathrm{~h}$ duration of mild hypothermia (defined as $32-35^{\circ} \mathrm{C}$ ) has shown that therapeutic hypothermia did not affect the clearance of gentamicin. Impaired renal function however, is strongly associated with serum gentamicin concentrations [41]. However, gentamicin clearance is decreased in neonates with HIE treated with hypothermia by up to $25 \%$ [42] compared with previous reports in non-asphyxiated normothermic fullterm neonates. A prolonged 36-hour dosing interval will be needed to achieve target gentamicin trough concentrations in this population [43]. Because hypothermia may increase the risk of infections, further studies are required to clarify the effect of hypothermia on the PK and PD of anti-infectives.

\section{CONCLUSIONS}

Mild to moderate hypothermia can cause a reduction in clearance and an increase in drug plasma concentration and this may cause harm and limit the benefits of this promising therapy. Further clinical pharmacokinetic and pharmacodynamic studies are essential for the development of substantiated dose regimens during therapeutic hypothermia to avoid toxicity and reduce the risk of therapy failure. Reducing the infusion rates of morphine, fentanyl, and propofol during therapeutic hypothermia is encouraged.

\section{CONFLICT OF INTEREST}

The authors confirm that this article content has no conflict of interest.

\section{ACKNOWLEDGEMENTS}

Thank you to Dr Jonathan Rhodes and Ms Morag Naysmith for help in preparing the Phenytoin data.

\section{REFERENCES}

[1] Cullen DJF, Sweitzer BJ, Bates DW, et al. Preventable adverse drug events in hospitalized patients: a comparative study of intensive care and general care units. Crit Care Med 1997; 25(8): 1289-97.

[2] Polderman KH. Mechanisms of action, physiological effects, and complications of hypothermia. Crit Care Med 2010; 37(Suppl. 7): S186-S202.

[3] Alderson P, Gadkary C, Signorini DF. Therapeutic hypothermia for head injury. Cochrane Database Syst Rev 2004; (4): CD001048.

[4] Polderman KH, Ely EW, Badr AE, Girbes AR. Induced hypothermia in traumatic brain injury: considering the conflicting results of meta-analyses and moving forward. Intensive Care Med 2003; 29: 1637-44.

[5] Qiu WS, Liu WG, Shen H, et al. Therapeutic effect of mild hypothermia on outcome of patients with severe traumatic brain injury. Chin J Traumatol 2005; 8: 27-32.

[6] Bernard SA, Gray TW, Buist MD. Treatment of comatose survivors of out-of-hospital cardiac arrest with induced hypothermia. N Engl J Med 2002; 346(8): 557-63.

[7] Hypothermia After Cardiac Arrest Study Group. Mild therapeutic hypothermia to improve neurological outcome after cardiac arrest. N Engl J Med 2002; 346: 549-56.

[8] American Heart Association. Guidelines for CPR and ECC. Part 7.5 post-resuscitation support. Circulation 2005; $112(24$ Supplement IV): 84-8.

[9] Zhang H, Zhou M, Zhang J, Mei Y, Sun S, Tong E. Therapeutic effect of post-ischemic hypothermia duration on cerebral ischemic injury. Neurol Res 2008; 30(4): 332-6.

[10] Shankaran S. Therapeutic hypothermia for neonatal encephalopathy. Curr Treat Options Neurol 2010; 14(6): 608-19. 
[11] Clifton GL, Miller ER, Choi SC, et al. Lack of effect of Induction of Hypothermia after Acute Brain Injury. N Engl J Med 2001; 344: 556-63.

[12] Clifton GL, Choi SC, Miller ER, et al. Intercenter variance in clinical trials of head trauma - experience of the National Acute Brain Injury Study: Hypothermia. J Neurosurg 2001; 95: 751-5.

[13] Clifton GL, Valadka A, Zygun D, et al. Very early hypothermia induction in patients with severe brain injury (the National Acute Brain Injury Study: II) a randomised trial. Lancet Neurol 2011; 10: 131-9.

[14] McIntyre LA, Fergusson DA, Hebert PC, Moher D, Hutchison JS. Prolonged therapeutic hypothermia after traumatic brain injury in adults: a systematic review. JAMA 2003; 289: 2992-9.

[15] Peterson K, Carson S, Cairney N. Hypothermia treatment for traumatic brain injury: a systematic review and meta-analysis. $\mathrm{J}$ Neurotrauma 2008; 25: 62-71.

[16] Polderman KH, Peerdeman SM, Girbes AR. Hypophosphatemia and hypomagnesemia induced by cooling in patients with severe head injury. J Neurosurg 2001; 94: 697-705.

[17] Koren GF, Barker CF, Goresky GF, et al. - The influence of hypothermia on the disposition of fentanyl--human and animal studies. Eur J Clin Pharmacol 1987; 32(4): 373-6.

[18] van den Broek MP, Groenendaal F, Egberts AC, Rademaker CM. Effects of hypothermia on pharmacokinetics and pharmacodynamics: a systematic review of preclinical and clinical studies. Clin Pharmacokinet 2010; 49(5): 277-94.

[19] Varon JF, Acosta P. Therapeutic hypothermia: past, present, and future. Chest 2010; 133(5): 1267-74.

[20] Fukuoka NF, Aibiki MF, Tsukamoto TF, Seki KF, Morita S. Biphasic concentration change during continuous midazolam administration in brain-injured patients undergoing therapeutic moderate hypothermia. Resuscitation 2004; 60(2): 225-30.

[21] Tortorici MA, Kochanek P, Kochanek PM, et al. Therapeutic hypothermia-induced pharmacokinetic alterations on CYP2E1 chlorzoxazone-mediated metabolism in a cardiac arrest rat model. Crit Care Med 2006; 34(3): 785-91.

[22] Heier TF, Caldwell JE, Sharma ML, Gruenke LD, Miller RD. Mild intraoperative hypothermia does not change the pharmacodynamics (concentration-effect relationship) of vecuronium in humans. Anesth Analg 1994; 78(5): 973-7.

[23] Heier TF, Caldwell JE, Sessler DF, Miller RD. Mild intraoperative hypothermia increases duration of action and spontaneous recovery of vecuronium blockade during nitrous oxide-isoflurane anesthesia in humans. Anesthesiology 1991; 74(5): 815-9.

[24] Leslie KF, Bjorksten AR, Ugoni A, Ugoni AF, Mitchell P. Mild core hypothermia and anesthetic requirement for loss of responsiveness during propofol anesthesia for craniotomy. Anesth Analg 2002; 94(5): 1298-303.

[25] Leslie KF, Sessler DF, Bjorksten AR, Moayeri A. Mild hypothermia alters propofol pharmacokinetics and increases the duration of action of atracurium. Anesth Analg 1995; 80(5): 100714.

[26] Bjelland TW, Klepstad P, Klepstad PF, et al. Effects of hypothermia on the disposition of morphine, midazolam, fentanyl, and propofol in intensive care unit patients. Drug Metab Dispos 2010; 41(1): 214-23.

[27] Bastiaans DE, Swart E, van Akkeren J. Pharmacokinetics of midazolam in resuscitated patients treated with moderate hypothermia. Int J Clin Pharm 2010; 35(2): 210-6.

[28] Koska AJ, III, Romagnoli AF, Kramer WG. Pharmacodynamics of fentanyl citrate in patients undergoing aortocoronary bypass. Cardiovasc Dis 1981; 8(3): 405-12.

[29] Tempelhoff RF, Modica PA, Bernardo KL, Edwards I. Fentanylinduced electrocorticographic seizures in patients with complex partial epilepsy. J Neurosurg 1992; 77(2): 201-8.

[30] Michelsen LG, Holford NH, Lu WF, Hoke JF, Hug CC, Bailey JM. The pharmacokinetics of remifentanil in patients undergoing coronary artery bypass grafting with cardiopulmonary bypass. Anesth Analg 2001; 93(5): 1100-5.
[31] Russell DF, Royston DF, Rees PH, Gupta SK, Kenny GN. Effect of temperature and cardiopulmonary bypass on the pharmacokinetics of remifentanil. Br J Anaesth 1997; 79(4): 456-9.

[32] Egan TD, Minto CF, Hermann DJ, Barr JF, Muir KT, Shafer SL. Remifentanil versus alfentanil: comparative pharmacokinetics and pharmacodynamics in healthy adult male volunteers. Anesthesiology 1996; 84(4): 821-33.

[33] Kurz AF, Go JC, Sessler DF, Kaer KF, Larson MD, Bjorksten AR. Alfentanil slightly increases the sweating threshold and markedly reduces the vasoconstriction and shivering thresholds. Anesthesiology 1995; 83(2): 293-9.

[34] Petros AF, Dunne NF, Mehta RF, et al. The pharmacokinetics of alfentanil after normothermic and hypothermic cardiopulmonary bypass. Anesth Analg 1995; 81(3): 458-64.

[35] Alcaraz CF, Bansinath MF, Turndorf HF, Puig MM. Hypothermia enhances the effects of morphine on hormonal and histamine release. Clin Exp Pharmacol Physiol 1989; 16(5): 367-74.

[36] Bansinath MF, Turndorf HF, Puig MM. Influence of hypo and hyperthermia on disposition of morphine. J Clin Pharmacol 1988; 28(9): 860-4.

[37] Puig MM, Warner WF, Tang CK, Laorden ML, Turndorf $\mathrm{H}$. Effects of temperature on the interaction of morphine with opioid receptors. Br J Anaesth 1987; 59(11): 1459-64.

[38] Roka AF, Melinda KT, Vasarhelyi B, et al. Elevated morphine concentrations in neonates treated with morphine and prolonged hypothermia for hypoxic ischemic encephalopathy. Pediatrics 2010; 121(4): e844-9.

[39] Iida YF, Nishi S, Asada A. Effect of mild therapeutic hypothermia on phenytoin pharmacokinetics. Ther Drug Monit 2001; 23(3): 192-7.

[40] Klamerus KJ, Rodvold KA, Silverman NA, Levitsky S. Effect of cardiopulmonary bypass on vancomycin and netilmicin disposition. Antimicrob Agents Chemother 1988; 32(5): 631-5.

[41] Liu XF, Borooah MF, Stone JF, Chakkarapani E, Thoresen M. Serum gentamicin concentrations in encephalopathic infants are not affected by therapeutic hypothermia. Pediatrics 2010; 124(1): 3105.

[42] Mark LF, Solomon AF, Northington FJ, Lee CK. Gentamicin pharmacokinetics in neonates undergoing therapeutic hypothermia. Ther Drug Monit 2010; 35(2): 217-22.

[43] Frymoyer AF, Meng LF, Bonifacio SL, Verotta DF, Guglielmo BJ. Gentamicin pharmacokinetics and dosing in neonates with hypoxic ischemic encephalopathy receiving hypothermia. Pharmacotherapy 2010; 33(7): 718-26.

[44] Sessler DI. Complications and treatment of mild hypothermia. Anesthesiology 2001; 95(2): 531-43.

[45] Caldwell JE, Heier TF, Wright PM, et al. Temperature-dependent pharmacokinetics and pharmacodynamics of vecuronium. Anesthesiology 2000; 92(1): 84-93.

[46] Beaufort AM, Wierda JM, Belopavlovic MF, Nederveen PJ, Kleef UW, Agoston S. The influence of hypothermia (surface cooling) on the time-course of action and on the pharmacokinetics of rocuronium in humans. Eur J Anaesthesiol Suppl 1995; 11: 95-106.

[47] Leslie KF, Sessler DF, Bjorksten AR, Moayeri A. Mild hypothermia alters propofol pharmacokinetics and increases the duration of action of atracurium. Anesth Analg 1995; 80(5): 100714.

[48] Diefenbach CF, Abel MF, Buzello W. Greater neuromuscular blocking potency of atracurium during hypothermic than during normothermic cardiopulmonary bypass. Anesth Analg 1992; 75(5): 675-8.

[49] Booth BP, Brien JF, Marks GS, et al. The effects of hypothermic and normothermic cardiopulmonary bypass on glyceryl trinitrate activity. Anesth Analg 1994; 78(5): 848-56.

[50] Andrews PJ, Sinclair HL, Battison CG, et al. European society of intensive care medicine study of therapeutic hypothermia (32-35 degrees C) for intracranial pressure reduction after traumatic brain injury (the Eurotherm3235Trial). Trials 2011; 12: 8. 